

El movimiento campesino en el Cauca: organización y lucha territorial por el reconocimiento como sujeto de derechos 


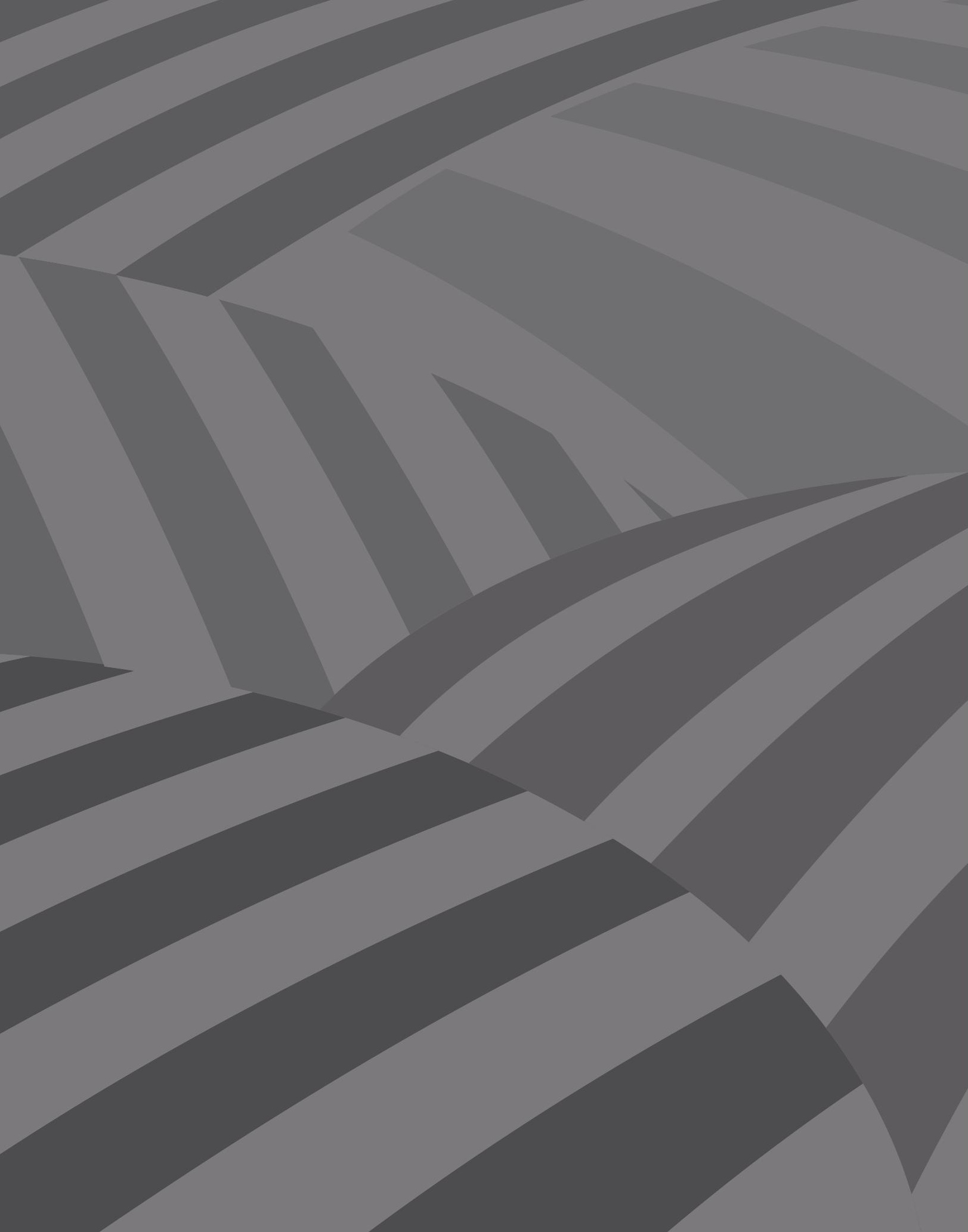




\title{
El movimiento campesino en el Cauca: organización y lucha territorial por el reconocimiento como sujeto de derechos*
}

\author{
Por Esneider Rojas**
}

\section{Introducción}

$\mathrm{E}$ l presente artículo recoge parte de los principales puntos de debate que se enmarcan en la Mesa campesina de concertación y negociación en el departamento del Cauca, en la cual participan organizaciones campesinas convergentes en el Proceso de Unidad Popular del Suroccidente Colombiano (Pupsoc) y el Comité de Integración del Macizo Colombiano (CIMA), el Estado y la Pontificia Universidad Javeriana de Cali ${ }^{1}$.

Esta Mesa surgió a finales del año 2012 con el objetivo de proponer soluciones concertadas a los conflictos territoriales e interculturales que se estaban presentando en el departamento entre las comunidades indígenas, negras y campesinas a causa de las aspiraciones territoriales de

* Artículo recibido en agosto de 2015

Artículo aprobado en noviembre de 2015

** Administrador de Empresas, Maestrante en Desarrollo Rural de la Universidad del Tolima. Desde el 2014 es Investigador del IEI en las líneas de Desarrollo Rural y Movimientos sociales. Ha participado en los proyectos de acompañamiento y secretaría técnica Mesas campesinas CIMA-PUPSOC, ANUC en el departamento de Córdoba y Cauca, Reformulación de las Unidades Agrícolas Familiares UAF, Diseño de un Sistema de Modelación Productiva en siete Zonas del Cauca.

1 Hay que aclarar que en el departamento del Cauca también existe una segunda mesa campesina, que corresponde a la Asociación Nacional de Usuarios Campesinos (ANUC). 
cada actor, los cuales se recrudecieron a raíz de la compra de predios por parte del Estado en el marco de sus acuerdos con las comunidades indígenas.

Así, en primera instancia, este artículo presenta un contexto general sobre las perspectivas del ordenamiento territorial de las organizaciones sociales del departamento del Cauca con el fin de plantear la proveniencia de las actuales reivindicaciones territoriales campesinas. En un segundo momento, se analizan las diversas acciones colectivas emprendidas por el campesinado desde los años ochenta para reivindicar la satisfacción de sus necesidades básicas. Finalmente, se presenta un análisis sobre el panorama actual del movimiento campesino, sus acciones políticas, sus propuestas territoriales y la exigencia de reconocer al campesinado como sujeto de derechos.

\section{Contexto de las organizaciones sociales: perspectivas territoriales en el departamento del Cauca}

Frente a los históricos conflictos sociales que atraviesa Colombia, han surgido distintas organizaciones y movimientos sociales que buscan reivindicar sus derechos territoriales y culturales; proceso cargado de encuentros y desencuentros. La población habitante del campo colombiano, en particular, ha conformado apuestas organizativas que proponen maneras diferentes de territorialidad encaminadas a garantizar la sobrevivencia y reproducción del campesinado, a la vez que realizan una profunda crítica al modelo agrario, productivo y de desarrollo que ha imperado en las políticas estatales.

En estas apuestas organizativas ha sido muy importante la exigencia de acceso a la tierra, la cual no se limita a disputar la propiedad sobre la misma, sino también a reconfigurar su uso. De esta manera, se han construido referentes identitarios que pasan por un proceso organizativo de cohesión social y van acompañados por la exigencia del reconocimiento 
de sus derechos, la elaboración de un discurso propio y la recuperación de la historia de la presencia y el poblamiento campesino.

En este sentido, la organización campesina enmarca su accionar frente a problemáticas como la concentración de la tierra, la cual en el 2009 alcanzó un 0,88 en el índice de Gini (IGAC, 2012), uno de los más altos del mundo. Lo anterior se suma a las políticas estatales y a un modelo de desarrollo que establece subsidios focalizados en lugar de inversión social, a la vez que prioriza el modelo empresarial. Así, los beneficios de la modernización han favorecido a los grandes productores en detrimento de los pequeños y de las comunidades rurales (PNUD, 2011).

En Colombia la extensión territorial es de 114 millones de ha, de las cuales 22 millones son de vocación agrícola, 15 millones de vocación ganadera y 48 millones de vocación forestal. Sin embargo, contrario a su vocación, en el uso del suelo encontramos que la agricultura ocupa 5,3 millones de hectáreas, frente a 34 millones en pastos y herbazales para ganadería y 0,4 millones de ha en forestales; cifras que demuestran la subutilización del suelo (IGAG, 2012). Es por esto que una de las principales exigencias de las organizaciones y centros de debate tiene que ver con la configuración del ordenamiento territorial, esencial para la consolidación de iniciativas productivas campesinas, indígenas y de pequeños productores.

La construcción territorial pasa por la posibilidad de gestionar y decidir sobre la explotación o no de los recursos; en este aspecto se ven enfrentados los intereses ambientales, productivos y de reproducción cultural de comunidades campesinas, indígenas y afros, con los intereses económicos y políticos de sectores empresariales nacionales e internacionales, como los representados en la locomotora minera y las Zonas de Interés de Desarrollo Rural Económico y Social (Zidres), impulsadas desde los diferentes gobiernos.

Como parte de la disputa territorial frente al modo de producción capitalista, que en el departamento del Cauca se expresa principalmente en 
la expansión de los monocultivos de caña de azúcar, eucalipto y pino agenciada desde el sector empresarial, las comunidades campesinas proponen no solamente acceso a tierras y formalización de la propiedad, sino además la consolidación de distintas figuras territoriales, como es el caso de las Zonas de Reserva Campesina (figura reglamentada en la Ley 160 de 1994) y, en años más recientes, la figura de los Territorios Agroalimentarios, impulsada por las organizaciones campesinas que hacen parte del Coordinador Nacional Agrario (CNA).

Las comunidades negras, organizadas en Consejos comunitarios reconocidos en la Ley 70 de 1993, la cual les garantiza la conformación de territorios colectivos principalmente hacia la Costa Pacífica, vienen exigiendo la conformación de territorios colectivos hacia los valles interandinos y Costa Caribe, donde hacen presencia organizativa y están constituidos legalmente. Por su parte, las comunidades indígenas cuentan con la figura territorial de los resguardos, amparados principalmente en la ratificación por parte de Colombia del Convenio 169 de la OIT y su adopción por medio de la Ley 21 de 1991 y la Ley 1152 del 2007, que reconocen las comunidades étnicas y reglamentan la constitución, ampliación y saneamiento de los resguardos.

Adicionalmente, en los últimos años las comunidades indígenas han iniciado la recuperación y la ratificación de títulos de resguardo de origen colonial y republicano, lo que ha propiciado la aparición de conceptos como territorios ancestrales o tradicionales, mencionados en los decretos autonómicos $\mathrm{N}^{\circ} 1953$ y 2333 del 2014. Esto ha llevado a que estas comunidades amplíen sus expectativas territoriales.

Dichas propuestas de ordenamiento territorial rural, asumidas por los movimientos sociales indígenas, campesinos y afros, han permitido la construcción de identidades y proyectos colectivos que tienen lugar en un "sistema multiculturalista, comprendido como una doctrina política que busca el reconocimiento y preservación de la diferencia social expresada en términos étnicos diferenciales” (Duarte, 2015, p.41). En este 
sentido, la construcción territorial de las comunidades rurales hace parte fundamental de los movimientos sociales que toman como referencia el marco de la Constitución Política de 1991 para exigir la garantía de sus derechos territoriales, como hacen las comunidades indígenas y negras, o la ampliación de estos derechos y su reconocimiento como sujetos sociales, en el caso de las comunidades campesinas.

El principal interés de las organizaciones campesinas de articularse al marco de derechos diferenciales radica en la posibilidad de contar con una herramienta jurídica que les permita acceder al territorio y ejercer gobernabilidad en un contexto donde prima una fuerte presión por el acceso a la tierra y el posicionamiento de aspiraciones territoriales por parte de las diferentes comunidades del departamento del Cauca.

Sin embargo, este acceso diferencial a los derechos ha traído consigo un proceso de enfrentamiento y de competencia entre los distintos grupos poblacionales rurales -indígenas, afrodescendiente y campesinos-, pues conlleva luchas por la tierra, el territorio y la gobernabilidad territorial ${ }^{2}$ a nivel local y regional por cada uno de los actores sociales que convergen en un mismo espacio físico ${ }^{3}$.

El acceso diferencial a derechos lleva a las comunidades rurales a remarcar su identidad, que se hace necesariamente en oposición a algún otro, e implica establecer unos límites en el ámbito político, simbólico, territorial y de derechos. Estos límites suponen también un proceso de negación del otro, ya sea de forma individual o colectiva: el otro no soy

2 Gobernabilidad entendida como la forma de administrar política y jurídicamente y de ejercer control social en los territorios de resguardo y zonas de influencia donde se pretende constituir.

3 Para ampliar información frente a los conflictos y competencias entre comunidades indígenas, campesinas y afros en el departamento del Cauca consultar el libro Desencuentros territoriales. La emergencia de los conflictos en el departamento del Cauca (Duarte, 2015). 
yo, porque yo soy de esta manera, y tú no eres parte de mi grupo porque no eres de esa manera ${ }^{4}$.

Estos distintos matices deben ser tenidos en cuenta a la hora de analizar la heterogeneidad del movimiento social en el departamento del Cauca. Así, podemos entender tanto las razones básicas por las cuales las organizaciones se encuentran, articulan y movilizan comúnmente, por ejemplo en la lucha por la tierra y en contra de proyectos mineroenergéticos y tratados de libre comercio que afectan directamente los territorios y sus procesos organizativos, como también sus propuestas de índole territorial, autonomía y gobernabilidad comunitaria, que se gestionan localmente y en ocasiones marcan caminos políticos diferentes y contrapuestos entre organizaciones.

\section{El movimiento campesino en el departamento del Cauca}

Para tratar de comprender el movimiento campesino en el departamento del Cauca, retomamos el concepto de movimientos populares que trabaja Norma Michi (2010), categoría amplia que aglutina sectores que son explotados económicamente y que se encuentran en situación de opresión política, exclusión y pobreza. Esta definición se acerca a la realidad de los actores que se analizan en este artículo, pero incluye también un enfoque más cercano y problematizador de las relaciones sociales. En el marco de estos movimientos, "el campesino se torna una expresión política utilizada por los mismos actores para reclamar o reivindicar derechos sociales que no les han sido otorgados por el estamento" (Tocancipá-Falla, 2005).

4 Sin embargo, hay una amalgama de actores: indígenas que se autorreconocen como campesinos, mestizos que se reconocen como indígenas, afros que se reconocen como indígenas. En muchos casos hay relaciones de familiaridad que se conflictúan cuando se asumen proyectos políticos y territoriales diferentes. En este sentido, a nivel regional y nacional se puede plantear que se construyen en oposición, pero a nivel local y veredal se niega al otro en un ámbito político y territorial. 
Partiendo de lo que propone Michi, hay tres dimensiones centrales para comprender este tipo de movimientos: el modo de vida campesino, sus acciones políticas y la territorialización (2010). Para el caso de esta investigación abordaremos sus acciones políticas, propuestas territoriales y la lucha por su reconocimiento como sujetos de derechos que sustentan la territorialidad campesina.

Si bien Michi aborda el análisis de los movimientos sociales a partir del campo de los movimientos populares, en nuestro caso tomamos ciertos elementos que nos propone Touraine al respecto:

el movimiento social es la acción, a la vez culturalmente orientada y socialmente conflictiva, de una clase social definida por su posición dominante o dependiente en el modo de apropiación de la historicidad, de los modelos culturales de inversión, de conocimiento y moralidad, hacia los cuales el mismo se orienta. (Touraine, 1984, p.99)

Estos elementos nos permiten entender las movilizaciones campesinas por el cumplimiento de las necesidades básicas, salud, educación y vías, iniciadas en los años ochenta, y su proceso de mutación-innovación hacia la exigencia de derechos políticos, territoriales, ambientales y culturales en las dos últimas décadas.

Desde esta perspectiva el campesino es un actor central en la dinámica rural que resiste en su entorno valiéndose de algunas dinámicas propias $\mathrm{y}$, a la vez, de propuestas territoriales que en muchos casos toman como referente la ruta de exigibilidad trazada por las comunidades indígenas y negras en términos de reconocimiento y acceso a derechos.

Las organizaciones campesinas que hacen parte del Pupsoc y del CIMA han construido a nivel regional, y en algunos casos local, escenarios de encuentro comunes para exigir el cumplimiento de sus derechos ante los diferentes gobiernos de turno. Esto les ha permitido construir propuestas conjuntas de inclusión y de negociación, ya sea en escenarios de interlocución auspiciados por el Estado o en escenarios de movilización 
mediante acciones de hecho, como la toma de vías, la recuperación de tierras y las asambleas permanentes, que han obligado al Estado a crear mesas de negociación y concertación de carácter regional, con presencia institucional del nivel central.

Los escenarios construidos desde las organizaciones campesinas como movimiento campesino en el departamento del Cauca se podrían enmarcar en los nuevos movimientos sociales. Como lo plantea Boaventura de Sousa, los protagonistas de estas luchas no son las clases sociales; son grupos sociales a veces mayores y a veces menores que las clases (2001). En este sentido, las comunidades campesinas vienen siendo protagonistas en la exigencia de reconocimiento y de acceso a la tierra por vía de mercado de tierras, como se evidencia en los talleres de cartografía social realizados en el 2014 con la Mesa campesina, donde proponen:

1. Compra de tierras para las familias campesinas que sean sujetos de reforma agraria, es decir, que no la poseen o la poseen de forma insuficiente.

2. Solución a los conflictos interétnicos e interculturales.

3. Conformación de territorialidades campesinas.

4. Inclusión en los programas estatales.

5. Reconocimiento del campesino como un sujeto de derechos amparados en la propuesta de derechos de los campesinos y campesinas presentada ante la ONU.

Dichas propuestas las fundamentan en sus formas de comprender y construir la realidad social a partir de la movilización local, regional y nacional, las escuelas de formación política y la construcción de planes de vida o desarrollo, que generalmente se presentan en disputa o en complemento con los espacios de poder político local y regional.

Con el fin de conocer los antecedentes de la Mesa campesina del Pucsoc y el CIMA, en el siguiente apartado abordaremos los procesos de movilización más representativos realizados entre mediados de los años 
ochenta y finales de los noventa, y su articulación con otros movimientos de carácter nacional e intersectorial.

Algunos datos históricos del proceso campesino CIMA/Pupsoc y su accionar político. Las luchas del movimiento campesino en el departamento del Cauca inician a principios de los años ochenta con acciones de carácter local para exigir la garantía de derechos básicos como la construcción de puestos de salud, hospitales y escuelas y el mejoramiento y construcción de vías (Tocancipá-Falla, 2005). Más adelante, hacia 1985, en lo que ahora constituye el municipio de Sucre se reúnen líderes de los municipios del Macizo Colombiano para trazar unos principios políticos que orienten el trabajo organizativo, creándose así el CIMA. En 1986 se realiza una acción regional con la Marcha de la bota caucana, a la cual siguen la movilización de Rosas, Cauca, en 1991, el paro de Timbío en 1996 y la movilización de 1999, conocida como el Gran paro del suroccidente colombiano, en el cual también participó el departamento de Nariño.

Esta última movilización traza un hito en la historia del departamento, ya que logra articular otros procesos, como el sindicato de profesores Asoinca, y organizaciones campesinas del norte, sur y oriente del Cauca afiliadas a la Federación Nacional Sindical Unitaria Agropecuaria (Fensuagro). Esta acción puntual surge a partir de algunos acuerdos políticos logrados entre organizaciones y la exigencia conjunta de acuerdos incumplidos por el Gobierno nacional.

El Gran paro del suroccidente colombiano mantuvo bloqueada durante veintisiete días en varios puntos del Cauca y del norte de Nariño la vía Panamericana, que conecta Colombia y Ecuador ${ }^{5}$. Fensuagro, cuyo proceso inicia en 1976 con la aprobación de su personería jurídica, participa de la movilización de 1999 realizando bloqueos en el norte y sur del departamento del Cauca. En este mismo año, y como uno de

5 Datos construidos a partir de entrevista realizada a Guido Albán Rivera Chicangana, líder comunitario del Municipio de Santa Rosa que hace parte del CIMA, en el 2015. 
los resultados de dicha movilización, se crea el Pupsoc, que para el año 2005 realiza acciones puntuales en el norte del Cauca con la toma de predios como las haciendas Japio y Miraflores.

En el 2006 se realiza una gran movilización del sur de Colombia, en la que participan organizaciones campesinas e indígenas del Valle del Cauca, Caquetá, Putumayo y Cauca. El año siguiente, el 2007, se bloquea la vía Panamericana a la altura del corregimiento de Mondomo, en el municipio de Santander de Quilichao. Por su parte, en el año 2008 el Pupsoc se moviliza en apoyo al paro de los corteros de caña en el municipio de Villa Rica y al paro de los indígenas que estaban concentrados en la vereda de la María, municipio de Piendamó.

En el año 2013, el Pupsoc participa nuevamente en el paro agrario nacional junto con el CIMA y las organizaciones campesinas representadas en las Dignidades cafeteras, paperas y lecheras movilizadas a nivel nacional. Como resultado de este proceso se crea en el departamento del Cauca una mesa de negociación llamada Mesa de Interlocución Agraria (MIA), compuesta por representantes del Pupsoc y del CIMA.

En el Paro nacional agrario y popular, que tuvo lugar en el año 2013 ${ }^{6}$, se presentaron propuestas políticas y reivindicatorias desde el departamento del Cauca que sirvieron de insumo para la agenda de negociación con el Gobierno nacional. Dichas propuestas se discutieron en un principio en la MIA, pero luego hicieron parte de la Mesa campesina CIMA/CNA-Pupsoc.

$6 \quad$ Los puntos de exigencia durante este paro fueron: implementación de medidas y acciones frente a la crisis de la producción agropecuaria; acceso a la propiedad de la tierra; reconocimiento a la territorialidad campesina; participación efectiva de las comunidades y los mineros pequeños y tradicionales en la formulación y desarrollo de la política minera; que se adopten medidas y se cumplan las garantías reales para el ejercicio de los derechos políticos de la población rural; y garantías en derechos humanos. 
En el contexto nacional, desde el 2010 se venía gestando la propuesta del Movimiento Social y Político Marcha Patriótica, donde confluyeron el Pupsoc y Fensuagro con más de 5000 personas. Esta propuesta, originada en la convergencia de los trabajadores de la caña de azúcar con la minga indígena, realizó en Bogotá, a principios de 2012, una concentración de más de ochenta mil campesinos, incluyendo indígenas, mestizos y afrodescendientes (Fajardo, 2014, p.150).

Para finales de la década del 2000, el CIMA y otras organizaciones locales del CNA confluyen en la Minga social y comunitaria de los pueblos y participan en la marcha a Cali, además de asambleas y encuentros regionales (tulpas) y nacionales. Esto lleva, en el 2010, a la conformación de la plataforma nacional del Congreso de los Pueblos en la ciudad de Bogotá.

El Pupsoc, Fensuagro, el CIMA y organizaciones locales filiales al CNA son organizaciones que representan a un conjunto de agrupaciones y asociaciones de campesinos, principalmente del nivel local (municipios, corregimientos y veredas), presentes en veintiocho de los $42 \mathrm{mu}$ nicipios del departamento del Cauca.

A nivel nacional, el Pupsoc hace parte de Marcha Patriótica y algunas de las asociaciones campesinas de carácter local que lo conforman integran la Asociación Nacional de Zonas de Reserva Campesina (Anzorc). Por su parte, el CIMA pertenece al CNA y converge en el Congresos de los Pueblos. Ambas organizaciones tienen voceros permanentes y hacen parte activa de la Cumbre agraria étnica y popular, escenario de convergencia social reconocido por el Gobierno nacional en el Decreto 870 de 2014.

Con los antecedentes de movilización del Pupsoc y el CIMA, y con base al pliego de reivindicación exigido en el año 2013 y el constante incumplimiento por parte del Gobierno nacional, se llevan los puntos exigidos a la agenda de la Mesa campesina departamental, que se abre en el 
año 2012 como mecanismo para solucionar los conflictos interétnicos e interculturales que se presentan en el departamento del Cauca, principalmente los relacionados con las perspectivas territoriales campesinas y el reconocimiento del campesino como sujeto de derechos.

\section{Las apuestas territoriales de las organizaciones campesinas Pupsoc/ CIMA-CNA en el departamento del Cauca}

En el marco de la negociación política de la Mesa campesina Pupsoc/ CIMA-CNA, las organizaciones campesinas vienen planteando la constitución de territorialidades campesinas en varias zonas del departamento del Cauca, cuyo objetivo central es salvaguardar la vida campesina, sus recursos naturales y la aspiración de un desarrollo político, económico y cultural autónomo que vaya en resistencia al modelo capitalista. En algunas zonas del departamento esta se plantea también como una contrapropuesta territorial del campesinado frente a la constitución, saneamiento y ampliación de resguardos por parte de las comunidades indígenas, en términos de qué actor social controla y gobierna el territorio.

En el departamento del Cauca la exigencia de conformación de ZRC tiene sus inicios en la movilización realizada hacia la ciudad de Bogotá y la toma de la Catedral Primada por parte de las comunidades campesinas en el año 2000. En ese momento se exigía la conformación de ZRC en los municipios de Páez, Inzá, Totoró, Corinto, Miranda y Caloto.

La lucha por la implementación de la figura de las ZRC tiene su origen en las movilizaciones cocaleras de 1996 en el sur de Bolívar y en el Caquetá y el Guaviare (Méndez, 2014, p.74). Entre los años de 1996 y 2002 se conformaron seis ZRC: Cabrera (Cundinamarca), El pato-Balsilla (Caquetá), Calamar (Guaviare), Bajo Cuembí y Comandante (Puerto Asís, Putumayo), Arenal y Morales (sur de Bolívar) y el Valle del Río Cimitarra (nordeste antioqueño y sur de Bolívar), dando cumplimiento a la Ley 160 de 1994 e institucionalizando la participación activa de las comunidades 
campesinas en el diseño e implementación de sus planes de desarrollo sostenible como elementos de autogestión.

En mayo del 2011 las organizaciones campesinas ${ }^{7}$ del oriente del Cauca ubicadas en los municipios de Páez, Inzá y Totoró solicitan de manera formal ante el Instituto Colombiano de Desarrollo Rural (Incoder) la constitución de ZRC. Ese mismo año las comunidades indígenas del departamento inician el estudio de clarificación de resguardos coloniales y republicanos, a cargo del Organización Internacional de las Migraciones (OIM), con el fin de determinar la viabilidad jurídica de los territorios indígenas constituidos en la época de la Colonia y ratificados en la República. Dichas aspiraciones territoriales exigidas por los distintos actores se superponen en varios municipios del Cauca, lo cual genera tensiones y conflictos territoriales a nivel local y regional.

Entre los años 2013 y 2014 las organizaciones campesinas del sur y norte del Cauca radican de manera formal la solicitud de conformación de ZRC en los siguientes municipios: Argelia, Patía, Balboa, Santa Rosa y la Vega, pertenecientes al sur del departamento, y en Caloto, Miranda y Corinto en la zona norte. Este proceso continuó en el 2015, momento en el que se suman solicitudes de los municipios de Cajibío y Piendamó, ubicados en el centro del departamento.

Por otro lado, en la IV asamblea nacional, realizada en el año 2013 en San Lorenzo, Nariño, el CNA plantea como estrategia territorial campesina los Territorios Agroalimentarios. En el marco de un taller con organizaciones campesinas del Cauca, facilitado por el Instituto de Estudios Interculturales-Pontificia Universidad Javeriana (IEI-PUJ) en 2014, estos fueron definidos como zonas estratégicas de economía campesina y agricultura familiar dedicadas a la producción de alimentos, la conservación del medio ambiente y la preservación de la cultura y vida digna campesina. Sin embargo, esta figura territorial todavía no se encuentra

Asociación Campesina de Páez (Ascamp), Asociación Campesina de Inzá Tierradentro (ACIT) y Asociación campesinos de Totoró (Asocat) 
reconocida ni reglamentada jurídicamente, ya que actualmente es una apuesta política del CNA.

En el siguiente mapa de Procesos Sociales Campesinos en el Departamento del Cauca se puede apreciar la presencia organizativa campesina y su propuesta de aspiración territorial. Las solicitudes de ZRC se ubican, hacia el sur de la Cordillera Central, en los municipios de Patía, Argelia y Balboa; hacia el centro, en los municipios de Piendamó y Cajibío; hacia el oriente, en los municipios de Páez, Inzá y Totoró; y hacia el norte, en los Municipios de Caloto, Miranda y Corinto. Por su parte, los Territorios Agroalimentarios se ubican, en el sur y centro del departamento, en los municipios de Santa Rosa, Florencia, Mercaderes, Bolívar, Almaguer, San Sebastián y Sucre, y, en el centro, en los municipios de Rosas, Timbío, Popayán, y Cajibío.

Otro aspecto a resaltar del mapa es la presencia de las organizaciones campesinas con su respectiva figura territorial: las que hacen parte del Pupsoc solicitan la conformación de ZRC desde principios del año 2000, mientras que las que conforman el CIMA-CNA legitiman Territorios Agroalimentarios desde el año 2014. Estas aspiraciones territoriales campesinas reconfiguran el ordenamiento territorial institucional imaginado, construido y trabajado desde la perspectiva de las organizaciones campesinas.

Los movimientos campesinos del Cauca y sus organizaciones han combinado dos tipos de luchas. La primera se da a partir de la acción directa en el sentido que lo plantea Touraine: "con acciones conflictivas que tratan de transformar las relaciones de dominación social ejercidas sobre los principales recursos culturales - la producción, el conocimiento, las reglas éticas - " (2016), las cuales ha asumido el movimiento social desde los años ochenta en sus diferentes luchas ante el Estado. La segunda se lleva a cabo a partir de los mecanismos de interlocución con el Estado establecidos en las mesas de negociación campesina, entendidas como instrumento para incidir en la política institucional. Con esta segunda forma de lucha no solamente se plantea una crítica directa al modelo 


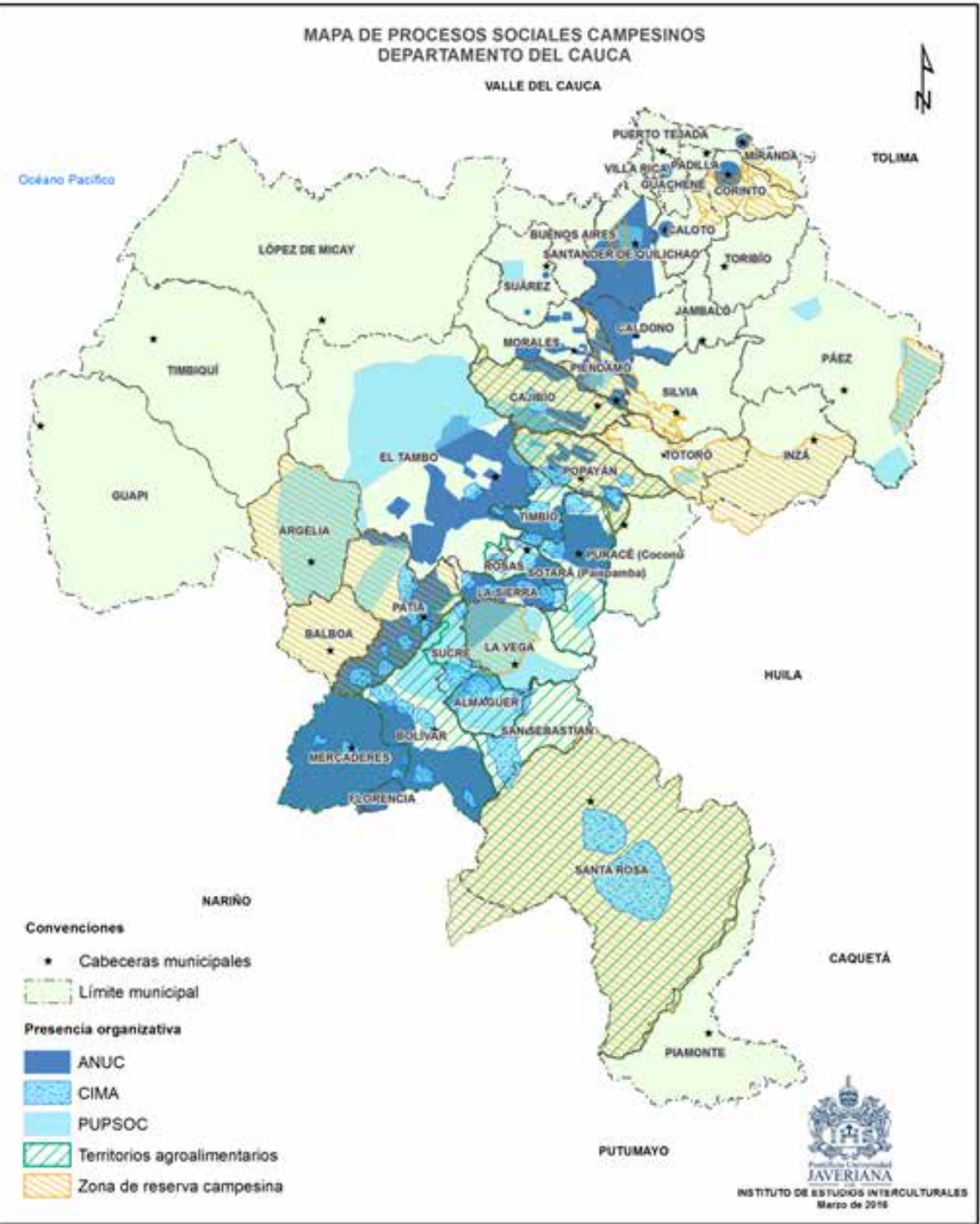

Fuente: Archivos Sistema de Información Geográfico. IEI, PUJ. 2016 
económico, sino también una ampliación de la política hasta más allá del marco liberal de la distinción entre Estado y sociedad civil (Sousa, 2001, p.181).

A partir de estas dos formas de lucha se plantea la necesidad de legitimar y formalizar las territorialidades propuestas por las organizaciones a partir de dos estrategias. La primera se orienta hacia el Estado: se basa en las exigencias y procesos de negociación por el reconocimiento de los derechos territoriales plasmados en la Ley 160 de 1994 y el Decreto 1777 de 1996, y en el posicionamiento político de los Territorios Agroalimentarios desde las comunidades campesinas.

La segunda estrategia se lleva a cabo a partir de la construcción política y organizativa en los territorios para legitimar las figuras a nivel social y comunitario. Al proponer ZRC o Territorios Agroalimentarios de hecho, las organizaciones sociales, asociaciones productivas y Juntas de Acción Comunal se convierten en las encargadas de planificar y ordenar el territorio; algunos ejemplos de ello se encuentran en los planes de desarrollo campesino de los municipios de Inzá, Páez, Totoró y La Vega, los cuales se encuentran articulados a los planes de gobierno de nivel municipal y departamental, y en el Plan de Vida, Agua y Dignidad del CIMA, que está en construcción desde el año de 1996.

Estas propuestas de construcción política y organizativa son también insumos para la negociación en las mesas, lo cual refleja su capacidad de formular propuestas frente a sus necesidades. Esto se puede observar en la siguiente cita, que surge como resultado de un taller con las organizaciones dinamizado por el IEI-PUJ en el marco de la Mesa, en donde se exigió que:

Se reconozca al campesino como un sujeto de conservación ambiental; pues en los territorios las comunidades-organizaciones campesinas han planificado y ordenado el territorio; zonas de producción agropecuaria, zonas de conservación y preservación de fuentes de agua (ojos de agua), linderos de quebradas y ríos. Por otro lado, el campesino preserva la biodiversidad 
a través de los sistemas sostenibles agroecológicos enfocados en la conservación y propagación de semillas propias, insumos orgánicos, intercambio solidario, saberes y tradiciones. (IEI-PUJ, 2014)

En este sentido, la Mesa campesina se ha planteado realizar un estudio de territorialidades campesinas donde se recoja la caracterización de los territorios campesinos, la tenencia de tierra y poblamiento campesino y la propuesta de decretos de los derechos de los campesinos ${ }^{8}$. Actualmente la Mesa se encuentra ejecutando dicho estudio.

Otro elemento que se negocia en la Mesa campesina es el acceso a tierras. Como resultado de ello, se han negociado con el Incoder (actualmente en liquidación) alrededor de 37 mil millones de pesos para adquisición de predios, ratificados en actas de 2012 y 2014', y la posibilidad de gestión de diez mil millones más. Con estos recursos económicos, para finales del 2015, se habían comprado 2320 hectáreas para familias campesinas asociadas a Pupsoc/CIMA-CNA.

Si bien se ha avanzado en la compra de tierras, con la ejecución de un $33 \%$ del presupuesto asignado, aún hace falta ejecutar un $67 \%$ del mismo. Este bajo nivel de ejecución presupuestal obedece, desde nuestra perspectiva, a los siguientes aspectos:

- Lentitud por parte de la institucionalidad estatal en el proceso de avalúos catastrales, rectificación y aclaración de áreas, análisis jurídico, entre otros, que evidencia la ineficacia institucional en el proceso de adquisición de tierras.

8 Esta información se encuentra en el acta de la reunión interministerial entre el Ministerio de Agricultura, el Ministerio del Interior y la Mesa campesina CIMACNA/Pupsoc, del 27 de octubre del 2014. Consultada en el archivo del IEI-PUJ de Cali.

9 Se hace referencia a esto en el acta de la reunión interministerial entre el Ministerio de Agricultura, el Ministerio del Interior y la Mesa campesina CIMA-CNA/Pupsoc, del 27 de octubre del 2014, y en el acta de la reunión entre la Mesa campesina y la 
- El proceso de adquisición de tierras es complejo, pues requiere de una rigurosa documentación a nivel predial que involucra la articulación interinstitucional entre entidades (Incoder, IGAC, Planeación Municipal, Registro de Instrumentos Públicos) que en muchos casos manejan información desactualizada y tienen poca coordinación en procedimientos y tipos de información.

- La necesidad de tierras, junto con la posibilidad de que el Gobierno destinara recursos para su compra, propició que en muchos casos los predios se ofertaran a más de dos organizaciones sociales (CRIC, ANUC, Pupsoc, CIMA, AICO, Mesa Territorial Afrocaucana), lo cual generó la suspensión del proceso con el fin de evitar conflictos interétnicos e interculturales.

En el marco de la adquisición de tierra, la Mesa campesina logró en el 2014 la modificación y cambio de las siguientes resoluciones emitidas por el Incoder: la Resolución 308 fue reemplazada por la 344 y la Resolución 266, por la 349 de diciembre del $2014^{10}$. La Resolución 344 reglamenta la entrega de proyectos productivos a las familias beneficiarias de subsidio de tierras y modifica su alcance con el fin de que las organizaciones campesinas, asociaciones productivas, cooperativas agropecuarias de primer y segundo nivel y empresas comunitarias puedan presentar, manejar y ejecutar los proyectos productivos de manera colectiva.

Por su parte, la Resolución 349 reglamenta los mecanismos para la entrega de tierras a familias beneficiarias y establece la posibilidad de que la tierra adquirida por parte del Incoder sea entregada de manera colectiva a las asociaciones campesinas, a través de la figura Común y proindiviso, si los beneficiarios o asociaciones de campesinos así lo solicitan. De esta manera, las organizaciones campesinas serán las que regulen y

10 Esta información quedó recogida en el acta de la reunión entre la Mesa campesina CIMA/Pupsoc y el Incoder, realizada en Popayán el 15 de julio del 2014, y el acta de la reunión entre la Mesa campesina del Cauca y la Dirección nacional del Incoder, realizada el 11 de septiembre de 2014. 
asignen tierra a las familias campesinas que cumplan con los requisitos de ser sujeto de reforma agraria.

La modificación de estas resoluciones, que reglamentan la entrega de proyectos productivos y la asignación de tierras por parte del Gobierno a las organizaciones campesinas o asociaciones productivas de manera colectiva, hace parte de los mecanismos técnicos, procedimentales y jurídicos que la Mesa campesina viene proponiendo en clave de facilitar su gestión y llenar de contenido, no solamente en un ámbito legítimo, sino también en un ámbito legal, las aspiraciones territoriales campesinas de ZRC y Territorios Agroalimentarios.

\section{Las perspectivas políticas: el campesinado como un sujeto de derechos}

El segundo elemento discutido y planteado en la Mesa campesina es el reconocimiento del campesino como sujeto de derechos, el cual está fundamentado en dos aspectos importantes: el derecho al territorio, abordado anteriormente, y la demanda de los campesinos a la sociedad y al Estado para que se les reconozca su condición de ciudadanos “con acceso pleno a todos sus derechos” (Forero et al., 2010, p.9). En este sentido, las organizaciones que hacen parte de la Mesa campesina plantearon en el taller de cartografía social realizado en el 2014 que es necesario que el Estado:

1. Reconozca la cultura campesina como fundamento central en la vida comunitaria del campesino.

2. Desarrolle una política rural que reconozca el modo de producción campesina de forma integral, con especial enfoque en lo cultural, social, ambiental y político.

3. Diseñe políticas públicas de desarrollo integral con enfoque territorial y diferenciado por grupos poblacionales: indígenas, afros, campesinos y empresarios.

4. Reconozca e incluya en la normatividad constitucional los derechos de los campesinos, los cuales deben contemplar los usos y tradiciones 
enmarcados en la identidad y en el campesino como sujeto de derechos.

5. Implemente políticas de desarrollo rural que respeten la biodiversidad, los recursos ambientales y el patrimonio social.

6. Promueva e implemente procesos de producción agroecológicos y autónomos.

7. Realice una reforma agraria integral y popular que satisfaga la necesidad de tierra de los campesinos sin tierra y de los que estén por debajo de la UAF.

Las organizaciones campesinas que hacen parte de la Mesa ponen de presente la necesidad de que se reconozca al campesinado colombiano como sujeto social de derechos y se lo saque de aquel discurso estatal desarrollista, economicista y productivista en el que se lo ha acomodado. En este sentido, la Mesa campesina aborda reivindicaciones de tipo cultural, comunitario, social, ambiental y político que sirven como aspecto diferenciador entre el campesinado y otros actores rurales y grupos étnicos. Lo anterior va en línea con lo propuesto por Salgado, quien afirma que "en el mundo rural no hay cultura sin la tierra, pero ella no es sin su entorno ecosistémico, cultural y las maneras de transformarlas” (Salgado, 2010, p.22).

Las organizaciones campesinas Pupsoc y CIMA-CNA, con el objetivo de avanzar en dicho reconocimiento, han definido dos estrategias. La primera de estas estrategias consiste en posicionar política y socialmente la Declaración de los derechos de las campesinas y campesinos ante las instituciones y la sociedad en general con campañas, foros académicos y seminarios. A través de estos, es posible dar a conocer el compendio de garantías jurídicas de protección a la vida campesina como alternativa rural en contraposición al modelo neoliberal, que atenta contra los recursos naturales, la justicia y el modo de vida rural. 
En este sentido, las organizaciones que actualmente hacen parte de la Mesa campesina han abierto espacios para la socialización y discusión del documento de la Declaración de los derechos de las campesinas y campesinos, propuesto por la Vía campesina desde el $2009^{11}$, la cual fue presentado ante las Naciones Unidas para su discusión. Esta Declaración se centra principalmente en:

El derecho a la vida y a un nivel de vida digna, a la tierra y el territorio, a las semillas y al saber y prácticas de agricultura tradicional, a medios de producción agrícola, a la información y a la tecnología agrícola, a la libertad para determinar los precios y el mercado para la producción agrícola, a la protección de valores en la agricultura, a la diversidad biológica, a la preservación del medio ambiente, a la libertad de opinión, y expresión y, al acceso de justicia. (Méndez, 2014, p.64)

Las demandas de las organizaciones de la Mesa campesina por el reconocimiento de los campesinos como sujetos de derechos, así como los derechos de los campesinos presentados ante la ONU, plantean la valorización de la vida campesina en la sociedad, lo cual reafirma lo planteado por Salgado (2010), quien afirma que el campesino es desprovisto de reconocimientos elementales, como por ejemplo ser sujeto cultural del desarrollo. Esto lleva al campesinado colombiano a exigir una ciudadanía plena, en el marco del engranaje estatal, como forma de resarcir la exclusión, segregación y desvalorización a las que ha estado sometido.

La segunda estrategia consiste en exigir al gobierno de turno el apoyo y la ratificación de los derechos de las campesinas y campesinos ante la

$11 \quad$ El avance del internacionalismo entre los movimientos rurales ha tomado forma con la constitución de organizaciones como el Congreso Latinoamericano de Organizaciones del campo (CLOC), la Asociación de Organizaciones Campesinas Centroamericanas para la Cooperación y el Desarrollo (ASOCODE), la Red Sudafricana de la Tierra (SANL) y la Vía Campesina, que es la de mayor presencia en el mundo (Bascuñan, 2009, p.162) 


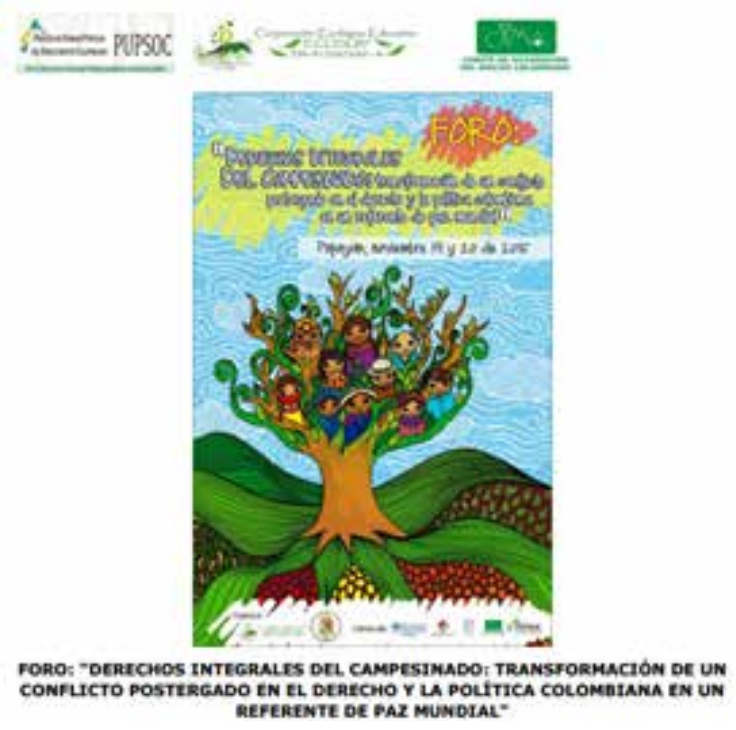

Afiche de convocatoria Pupsoc/Cima. 2015

ONU, lo que ha llevado a la Mesa campesina a dialogar con delegados de la Cancillería y el Ministerio del Interior en varias reuniones en las cuales se les ha exigido la aprobación de un proyecto de ley o una directiva gubernamental nacional en la que se reconozcan estos derechos ${ }^{12}$.

Para construir bases conceptuales y dar la discusión académica y política sobre este tema, en dirección a fortalecer un posible proyecto de ley, la Mesa campesina planeó realizar siete foros regionales en universidades públicas del país que permitieran impulsar el debate académico como insumo para los lineamientos generales del decreto ley que apruebe los derechos de los campesinos, pero hasta ahora solamente se ha realizado uno de estos, debido a que la financiación de los foros no fue realizada por el gobierno nacional, como quedo acordado en dicha mesa. El objetivo de los

12 En el acta de la reunión entre el Viceministerio del Interior, el Incoder, la Mesa campesina CIMA-CNA/Pupsoc y la ANUC Cauca, realizada el 12 de marzo del 2014, queda constancia de estas exigencias. 
foros es buscar el apoyo y vincular al debate a las organizaciones campesinas, los centros académicos y la sociedad en general para construir el documento general de los derechos de los campesinos.

En esta misma línea, en octubre del 2014 el senador Alberto Castilla lideró la primera audiencia en el Congreso de la República con el fin de posicionar en los espacios representativos de carácter nacional la propuesta del reconocimiento político del campesino como sujeto de derechos. De igual forma, en abril del 2016 el senador Castilla y las organizaciones campesinas radicaron un proyecto de reforma constitucional en la que se propone el reconocimiento del campesinado colombiano como sujeto de derechos y se le garantiza el derecho al acceso a la tierra y a la territorialidad campesina (Castellanos, 2016). Ese día hicieron presencia dirigentes y voceros de la Mesa campesina.

En síntesis, el movimiento campesino organizado del departamento del Cauca viene exigiendo su reconocimiento como sujeto de derechos en tres escenarios de participación política en los cuales los movimientos sociales posicionan sus demandas ante la sociedad y el Estado:

1. Mesas de negociación e interlocución con el Estado.

2. Movilización, foros, paros, asambleas comunitarias.

3. Espacios de representación política en lo parlamentario.

En palabras de Álvarez (como se citó en Ramírez, 2006, p.142):

los movimientos sociales proveen a los excluidos política y socialmente [...] espacios públicos críticos y alternativos en los cuales ellos pueden re/ construir identidades culturalmente estigmatizadas y aún más vilipendiadas y reclamar su "derecho a tener derechos" no sólo de servicios sociales, sino de dignidad humana, diferencia cultural y/o equidad social.

El movimiento campesino y el proceso de la Mesa campesina en el departamento del Cauca han permitido consolidar los procesos organizativos 
con sus respectivas propuestas de índole territorial y de reconocimiento político ante el Estado y la sociedad en general a través de mecanismos formales que fortalecen la democracia participativa. Sin embargo, dichos mecanismos solo son posibles en la medida en que los movimientos campesinos se movilicen en acciones colectivas que les permitan visibilizar sus problemáticas y propuestas.

\section{Reflexiones finales}

El movimiento campesino del Cauca se construye a partir de la legitimidad social en el territorio mediante estructuras organizativas locales, como las Juntas de Acción Comunal, asociaciones campesinas y productivas, la Junta de acueductos comunitarios, asociaciones de mujeres y de padres de familia; mecanismos de participación y decisión en las asambleas comunitarias; y foros y reuniones locales. Estos mecanismos legítimos permiten aproximarse a lo que las mismas organizaciones proponen como la posibilidad de ejercer control y gobernabilidad en los territorios. Como resultado de lo anterior, las organizaciones campesinas promueven la constitución de territorialidades campesinas en ZRC y Territorios Agroalimentarios.

Las organizaciones que hacen parte del Pupsoc y del CIMA-CNA han empleado diversos mecanismos para la exigencia de sus derechos: algunos entrelazan espacios de interlocución y negociación, como la Mesa campesina; otros conjugan espacios de movilización con acciones colectivas, como los paros, bloqueos de vías y asambleas permanentes; y otros hacen uso de los espacios de representación política, como el Congreso de la República. Dichos espacios les han permitido interactuar, concertar con el Estado y vincular a otros sectores sociales, como el caso de las comunidades indígenas, afros y campesinas.

El movimiento campesino tiende "A fundar una cultura política y, en última instancia, una nueva calidad de vida personal y colectiva basadas en la autonomía y en el autogobierno, en la descentralización y en la democracia participativa” (de Sousa, 2001, p.181). Este es un mecanismo 
para llevar el Estado a los territorios a través de la participación política directa en acciones de hecho o mesas de interlocución que permitan procesos efectivos de descentralización política, presupuestal y una planificación acorde con las realidades que viven los campesinos.

La Mesa campesina Pupsoc/CIMA-CNA es un espacio que les permite a las organizaciones converger con sus propuestas políticas, solucionar diferencias y asumir propuestas conjuntas para dialogar con el Estado, las organizaciones indígenas y afros y la sociedad en general. Además, se convierte en un referente organizativo político de unidad, de negociación y seguimiento a los acuerdos firmados entre el Gobierno y las comunidades.

\section{Bibliografía}

Archila, M. y Pardo, M. (2001). Movimientos sociales, Estado y democracia. Bogotá: Centro de Estudios Sociales de la Universidad Nacional de Colombia.

Archivo del Institutos de Estudios Interculturales de la Pontificia Universidad Javeriana de Cali. Actas y relatorías $(2012$ - 2016).

Archivo de la Asociación Campesina de Inzá Tierradentro - ACIT. Actas (1999 - 2016).

Castellanos, J.S. (15 de abril de 2016). Desde Colombia con las comunidades campesinas en resistencia. Agencia Prensa Rural. Recuperado de http:// www.prensarural.org/spip/spip.php?article19144

Duarte, C. (2015). Desencuentros territoriales, la emergencia de los conflictos interétnicos e interculturales en el departamento del Cauca. Bogotá: Instituto Colombiano de Antropología e Historia.

Fajardo, D. (2014). Las guerras de la agricultura colombiana 1980-2010. Bogotá: ILSA.

Forero, J., (Ed.). (2010). El campesino colombiano, entre el protagonismo económico y el desconocimiento de la sociedad. Bogotá: Pontificia Universidad Javeriana. 
Instituto Geográfico Agustín Codazzi (IGAC). (2012). Atlas de la distribución de la propiedad rural en Colombia. Bogotá: Imprenta Nacional de Colombia.

Méndez, Y. (2014) Derechos de los campesinos al territorio, justicia y zonas de reserva campesina, la experiencia del valle del río Cimitarra. Bogotá.

Michi, N. (2010). Movimientos campesinos y educación. El movimiento de los trabajadores rurales sin tierra y el movimiento campesino de Santiago del Estero-VC. Buenos Aires: El colectivo.

Programa de las Naciones Unidas para el Desarrollo (PNUD). (2011). Colombia rural. Razones para la esperanza. Bogotá: INDH-PNUD.

Ramírez, M. (2006) Los movimientos cívicos como movimientos sociales en el Putumayo: el poder visible de la sociedad civil y la construcción de una nueva ciudadanía.

Tocancipá-Falla, J. (2005). El retorno de lo campesino. Una revisión sobre los esencialismos y heterogeneidad en la Antropología. Revista Colombiana de Antropología, 41, 7-41.

Touraine, A. (1984). El Regreso del actor. Recuperado de http://repository. unad.edu.co/bitstream/10596/5377/1/Touraine \% 20-\% 20El \% 20regreso $\% 20$ del $\% 20$ Actor.pdf

Santos, B. (2001). Los nuevos movimientos sociales. Revista OSAL, (5), 177188. 